\title{
السجود على السجادة الحلديثة المرتفعة \\ للمرضى ونحوهم \\ Prostration on the modern \\ raised carpet for patients and the like
}

\author{
كئم إعداد الدكتورة \\ مها بنت عبدالله بن إبراهيم العبودي \\ Maha Abdullah Al-Aboudi \\ أستاذ مشارك بقسم الفقه بكلية الشريعة بالرياض \\ الملكة العربية السعودية
}


=

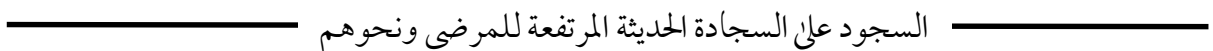


السجود على السجادة الحديثة المرتفعة للمرضى ونحوهم مها بنت عبدالله العبودي قسم الفقه، كلية الشريعة بالرياض، جامعة الإمام محمد بن سعود الإسلامية ، الرياض ، المملكة العربية السعودية. البريد الإلكتروني: maalabody@imamu.edu.sa الملخص: الصلاة عمود الدين، وهي الأساس للدين القويم، وعليها مدار صلاح العمل وفساده، وإليها يسند إيمان المرءء وكفره، فمن تركها فقد كفر . لم تسقط في

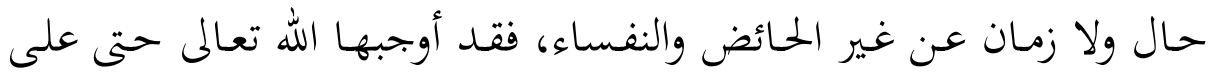
المقاتلين في أرض المعارك؛ رغم سيل الدماء واحتدام القتال ووقع النصال على ونى

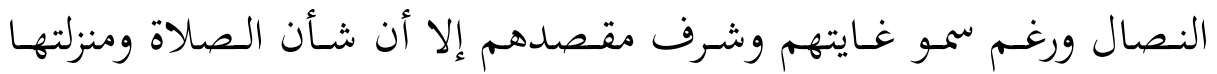
أعلى، ومقامها أرفع وأجل شأناً. لكن الشارع شرع فيها التيسير لهم ولغيرهم

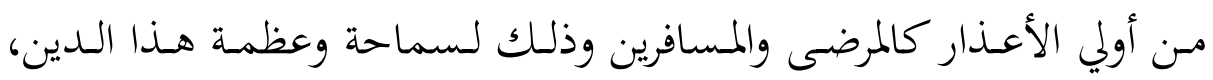

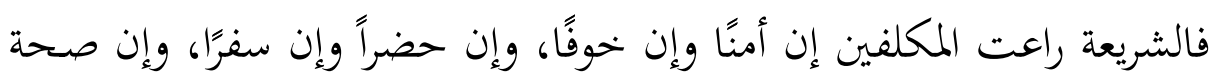

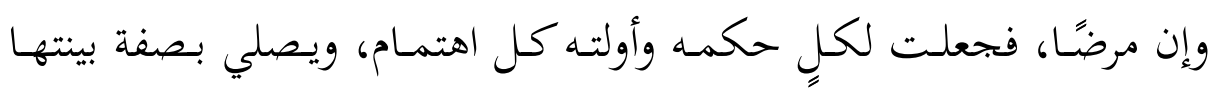

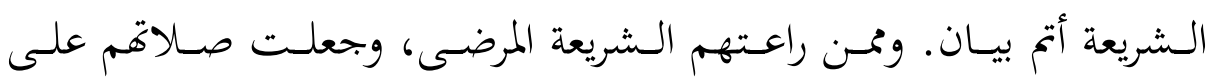

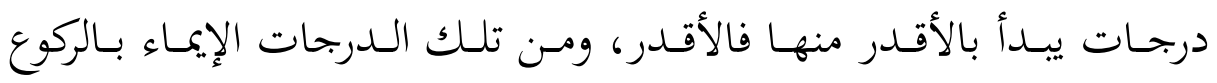
والسجود، وقد تم تصنيع كراسي مختصة يرتبط بها أصل صلب أشبه بالطاولة قد تتصل بالكرسي وقد تنفصل عنه، لكنها تمكن المصلي من السجود عليها

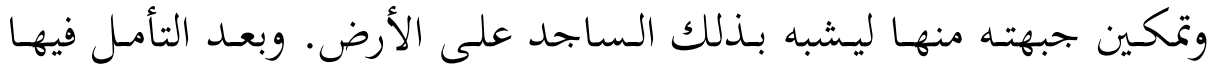

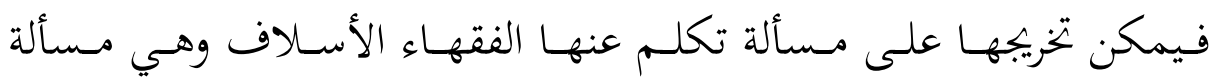


=

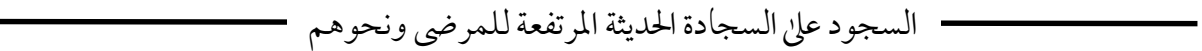

السجود على الموضع المرتفع أو الوسادة المرتفعة إذ الصورة واحدة، وقد انتهى بحـث هـذه المسألة إلى كراهـة السـجود على الوسـادة المرتفعـة وعليـه فيكـره السجود على السجادة الحديثة المرتفعة.

الكلمـات المفتاحيـة: حكـم السجود ، السسجادة ، الحديثـة ، المرتفعـة ،

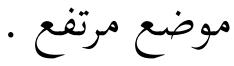




\section{Prostration on the modern raised carpet for patients and} the like

Maha Abdullah Al-Aboudi

Department of Jurisprudence, College of Sharia in Riyadh, Imam Muhammad bin Saud Islamic University, Riyadh ,Kingdom of Saudi Arabia.

Email: maalabody@imamu.edu.sa

\section{Abstract:}

Prayer is the pillar of religion, and it is the foundation of the orthodox religion, and on it is the course of goodness and corruption of work, and to it is based one's faith and unbelief, so whoever abandons it has committed disbelief. It did not fall under one condition or time on the one other than the menstruating woman and the postpartum woman, as God Almighty has enjoined it even on the fighters on the battlefield; Despite the torrent of blood and the fierce fighting, and the blades fell on the blades, and despite the loftyness of their goal and the honor of their goal, the importance and status of prayer is higher, and its place is higher and revered. But the legislator legislated it to facilitate for them and for others of the first excuses, such as the sick and travelers, for the tolerance and greatness of this religion. The Sharia took into account the duty bearers if they were safe and if they were fearful, and if they were present and if they traveled, and if they were health and if they were sick, so it made for each his judgment and gave him every attention, and he prayed in a manner that the Shariah explained in the most complete statement Among those who were taken care of by Sharia are the sick, and made their prayers in degrees, starting with the one who is able to do so, and then the most able, and among those 
degrees is the gesture of bowing and prostrating. Kneeling on the ground. After meditating on it, it can be concluded on an issue that the ancestors of the jurists spoke about, which is the issue of prostrating on a raised place or on a raised pillow, since the image is one, and the discussion of this issue ended with the dislike of prostrating on a raised pillow and therefore prostration on a raised modern carpet is disliked

Keywords: prostration , carpet , modern , raised, high position 


\section{بسم الله الرحمن الرحيم \\ المقدمة}

الحمد لله الذي رفع الحرج بهذا الدين، والصلاة والسلام على المبعوث رحمة للعالمين، وعلى آله الطيبين الطاهرين، وعلى مـن سـار على مـنهجهم واتبع هداهم إلى يوم الدين. أما بعد:

فإن الصلاة عمدود الدين، وهي الأسـاس للدين القويم، وعليها مـدار صلاح العمل وفساده، وإليها يسند إيمان المرء وكفره، فمن تركها فقد كفر.

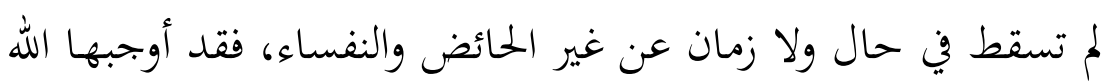
تعالى حتى على المقاتلين في أرض المعارك؛ رغم سيل الدماء واحتدام القتال

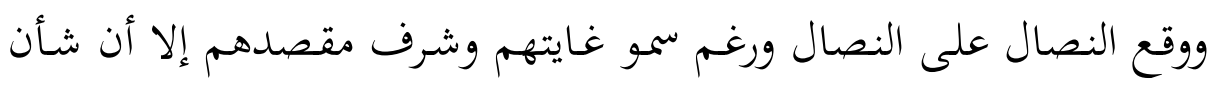
الصلاة ومنزلتها أعلى، ومقامها أرفع وأجل شأناً.

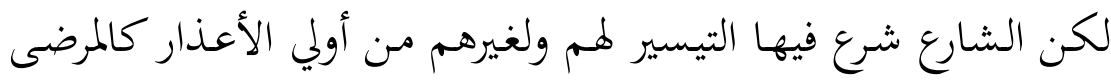

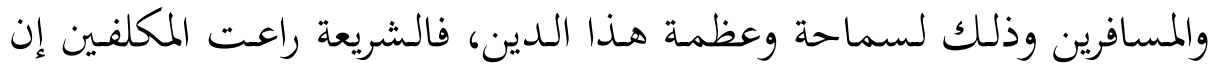

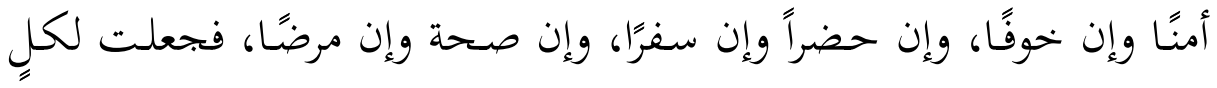
حكمه وأولته كل اهتمام، ويصلي بصفة بينتها الشريعة أتم بيان.

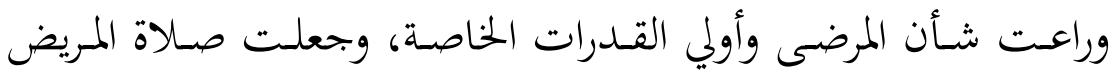
درجات ينتقل منها حسب الاستطاعة، ومنها الإيماء إيماءً بالركوع والسجود وروي 
فلا يلصق جبهته بالأرض عند السجود.

ومن هنا صنع المصنعون سجادة مرتفعة يتمكن منها المريض من وضع جبهته على موضع صلب كمـا لو كان يسجد على الأرض، وتساءل النـاس عن حكم ذلك فانتدبت نفسي لبحثث المسألة وبتحليتها لا سيما مع انتشار هذه السجادة، مستعينة بالله وحده ومستمدة توفيقه وفضله في تأصيلها وردها إلى القواعد الشرعية التي يمكن بناء حكم المسألة عليها. وقـد كـان فقهاؤنـا الأسـالاف يفترضـون المسائل قبـل حـدوثها ويبينـون الحلكم فيها أو الحلول الناجعة لها، فإذا ما وقعت المسألة عرفوها وعرفوا كيف الـدخول فيها والخهروج منها، وكانـت تلـك الافتراضـات بحـالاً خهبًا لإبـراز مقاصـد السشريعة الإسـلامية وتعليـل الأحكـام وبيـان صـالاحيتها لكـل زمـان ومالعتها لكل مكان مهما استجد فيهما، ولتبنى عليها مسسائل مستسجدة ويُشّزج النظير على النظير، ولم يحدث أن نزلت نازلة فوقف أهل العلم حيارى لم يتوصلوا إلى القول الصواب -إن شاء الله فيها-. وقد سرت في هذا البحث على الخطة التالية: المقدمـة وتسشتمل على : أهيـة الموضسوع، وسـبب اختيـاره، وخطـة البحـث والمنهج المتبع فيه. المبحث الأول: التعريف بمصطلحات البحث، وفيه مطلبان: المطلب الأول: التعريف باعتباره مفردًا، وفيه أربع مسائل: المسألة الأولى: تعريف السجود. المسألة الثانية: تعريف السجادة. 


$$
\text { المسألة الثألة الرابعة: تعريف تعريف المحديثة. }
$$

المطلب الثاني: التعريف باعتباره مركبًا.

المبحث الثاني: حكم السجود على موضع مرتفع. المبحث الثالث: حكم السجود على السجادة المرتفعة الحديثة. الخاتمة: وفيها أهم نتائج البحث. تم فهرس المصادر والمراجع.

وقد اتبعت في هذه الدراسة منهجًا محددًا أبرز ملامحه ما يأتي:

$$
\text { - الاعتماد على أماكن المصادر والمراجع الأصلية. }
$$

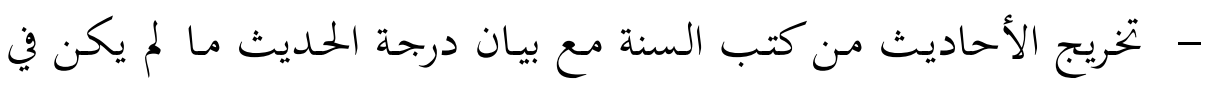

$$
\text { الصحيحين أو في أحدهما. }
$$

- - الاقتصار على المذاهب الفقهية المعتبرة. - - بحث المسألة الخلافية والاجتهاد في الاستدلال لكل قول ومناقشة الأدلة

$$
\text { ثم بيان الراجح. }
$$

- العناية بقواعد اللغة العربية والإملاء وعلامات الترقيم. - الترجمة للأعلام غير المشهورين.

وبعد، فدونك هذا البحث قد أفرغت فيه وسعي وبذلت له جهدي، فإن وفقت فمن الله وحده، وإن تكن الأخرى فما إلى ذلك قصدت، والك والله أسأل أن يغفر الزل والتقصير. 


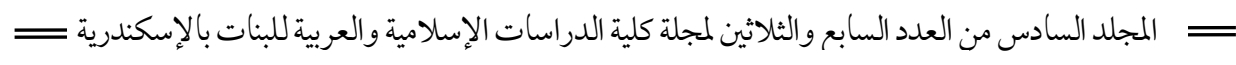

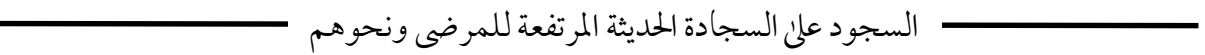

وكان الفراغ منه يوم الجمعة ليلة السبت لعشر ليال بقين من شهر ذي

الحجة من السنة الثانية والأربعين بعد الأربعمئة والألف من الهجرة النبوية على

صاحبها أفضل الصلاة وأزكى السلام.

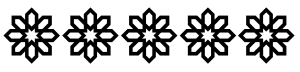




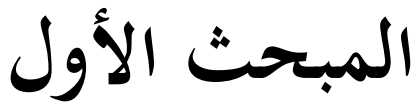

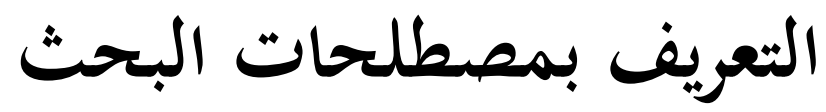

وفيه مطلبان:

المطلب الأول: التعريف باعتباره مفردًا.

المطلب الثاني: التعريف باعتباره مركبًا. 


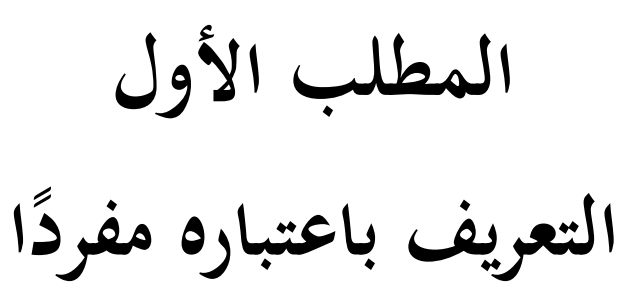

وفيه أربع مسائل:

المسألة الأولى: تعريف السجود.

المسألة الثانية: تعريف السجادة.

المسألة الثالثة: تعريف الحديثة.

المسألة الرابعة: تعريف المرتفعة.

$\overline{\overline{2}} 9 \wedge=$ 


\section{المسألة الأولى: تعريف السجود لغةً واصطلاحًا:}

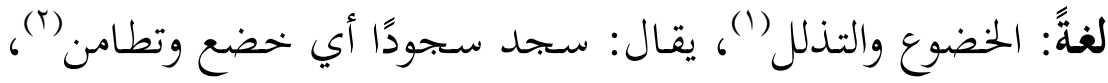

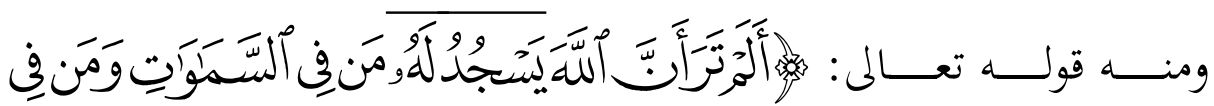

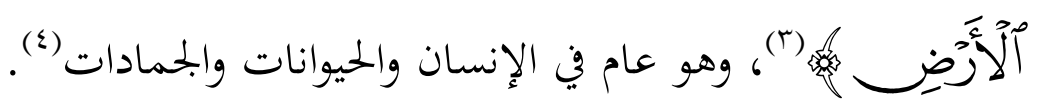

قال ابن فارس(0) -رحمه الله-: (السين والجهيم والدال أصل واحد مطرد

يدل على تطامن وذل، يقال: سجد إذا تطامن) (ج).

السجود اصطلاحًا:

وضع الجبهة على قصد العبادة"(V).

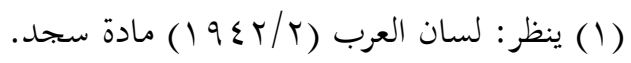

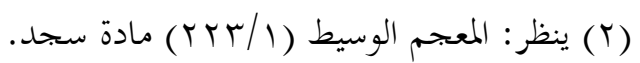

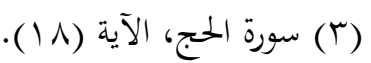

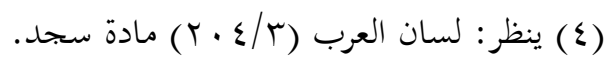

(0) ابن فارس: أممد بن فارس بن زكريا أبو الحسين الرازي، من أكابر أثمة اللغة كادئ كان فقيهًا

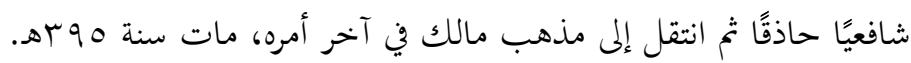
من مصنفاته: مقاييس اللغة، البحمل في اللغة، حلية الفقهاء.

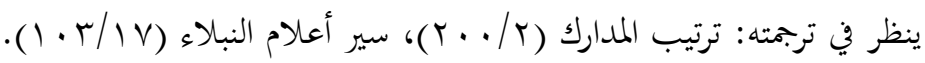

(7) مقاييس اللغة (T/T/T (1 ).

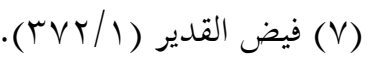




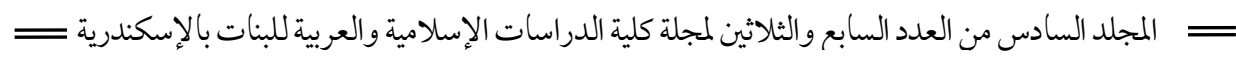

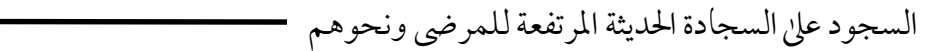

وقيـل: وضـع الجبهـة وغيرهـا مـن أعـضاء السجود على الأرض على قصد

(1) (1) (1)

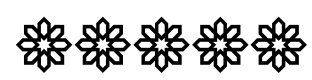

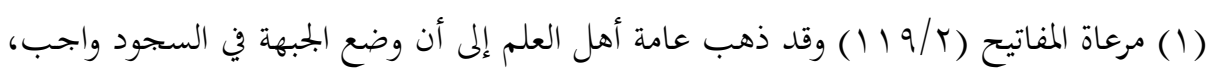

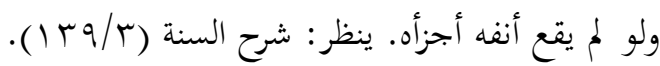




\section{المسألة الثانية: تعريف السجادة لغة واصطلاحًا.}

لغة: قال ابن فارس -رحمه الله-: (السين والجيم والدال أصل واحد مطرد

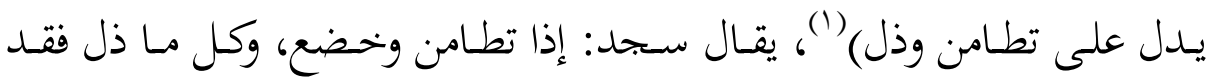

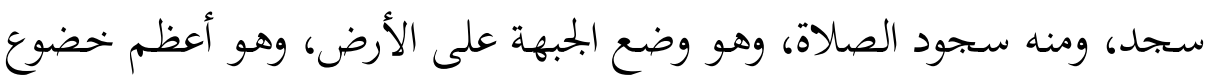
وهو عبادة الله وحده (r).

اصطلاحًا: قماث ونحوه يصلى عليه وهي المكان المسجود عليه (ب).

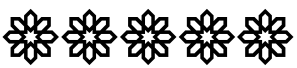

$$
\begin{aligned}
& \text { (1) مقاييس اللغة (T/T / I ) مادة سجد. }
\end{aligned}
$$

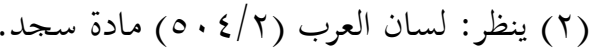

$$
\begin{aligned}
& \text { (Y) (Y) (Y) (Y) }
\end{aligned}
$$




\title{
المسألة الثالثة: تعريف الحديثة لغةً واصطلاحًا.
}

لغة: قال ابن فارس -رحمه الله-: (الحاء والدال والثاء أصل واحد، وهو

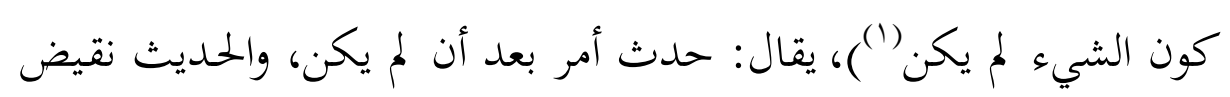

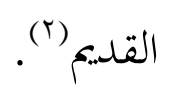

اصطلاحًا: وجود الشيء بعد العدم (r).

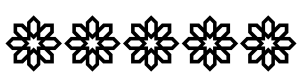

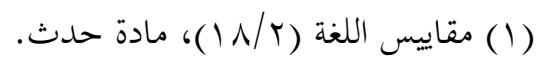

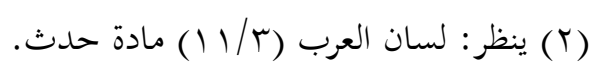

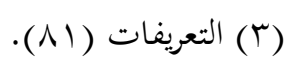


المسألة الرابعة: تعريف المرتفعة لغةً واصطلاححًا.

لغة: مرتفعة، اسم فاعل من ارتفع والتاء زائدة للتأنيث، يقال رفعت

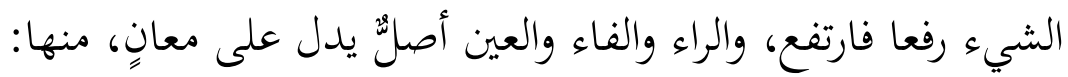
1 - ما كان خلاف الخفض والوضع. r- ب إذاعة الشيء وإظهاره. r- التقديم، يقال: رفعت قصتي إذا قدمتها.

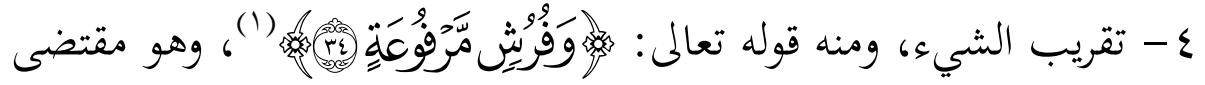
اسم الله سبحانه وتعالى: "الرافع" الذي يرفع المؤمن بالإسعاد وأولياءه

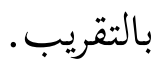
ه- المبالغة في السير، يقال: رفع البعير في السير، إذا بالغ (r). اصطلاحا: ما كان نقيض الخفض في كل شيء

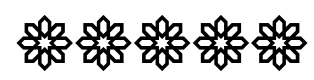

(1) [بورة الواقعة: ؟r]

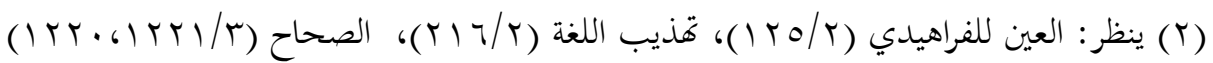

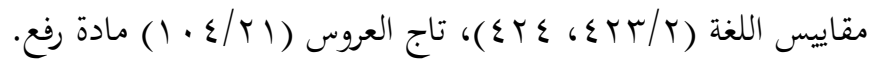

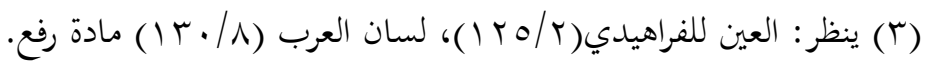




\section{المطلب الثاني: التعريف باعتباره مركبًا.}

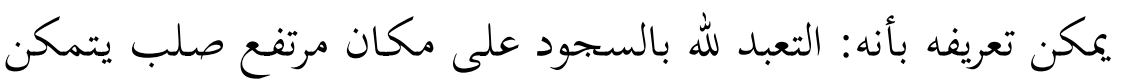

المصلي من ملاصقة جبهته به، وذلك للمرضى ومن في حكمهم.

وهذه صورة توضيحية للسجادة المقصودة:

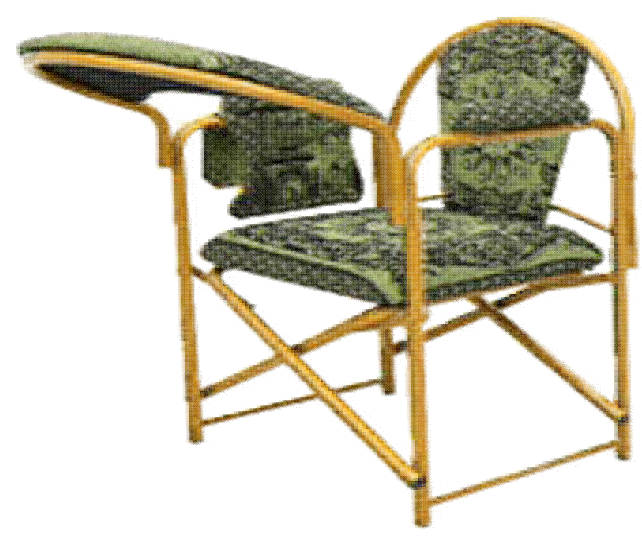




\section{المبحث الثاني}

\section{حكم السجود على موضع مرتفع}

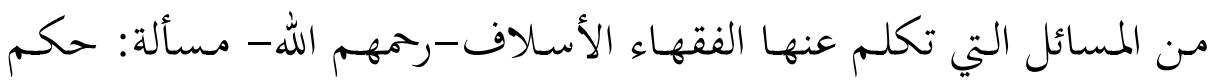

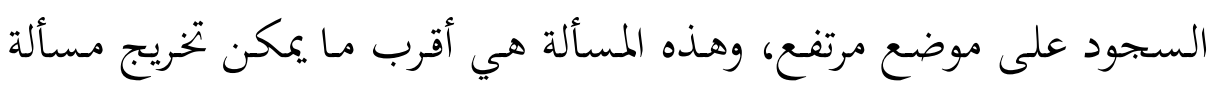
البحث عليها، فوجب الوقوف على كلام أهل العلم عليها أولاً.

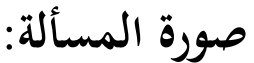

إذا لم يتمكن المصلي من وضع جبهته على الأرض لمرض ونحوه فرفعت

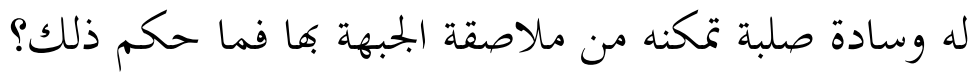

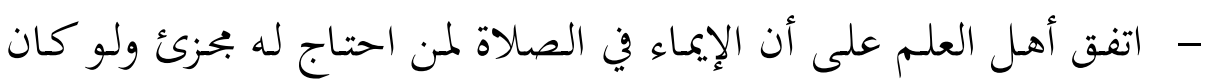
على موضع مرتفع أو وسادة مرتفعة (1).

واتفقوا على أن السجود على موضع مرتفع من غير إيماء ولا انحناء لا

يجزئ ولا تصح به الصلاة(؟).

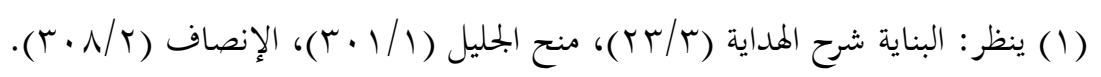

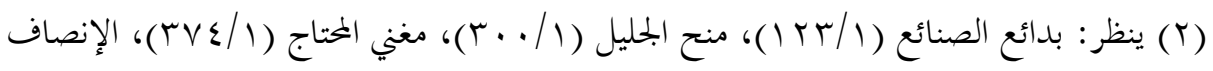

$$
\cdot(r \cdot V / r)
$$


واختلفوا في حكم الفعل لمن احتاج له على ثلاثة أقوال:

القـول الأول: يهـرم ســود المـومئ على الموضـع المرتفـع أو الوســادة

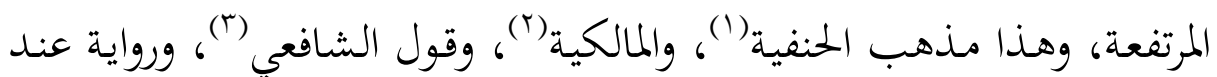

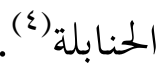

أدلة هذا القول: (0) - (0)

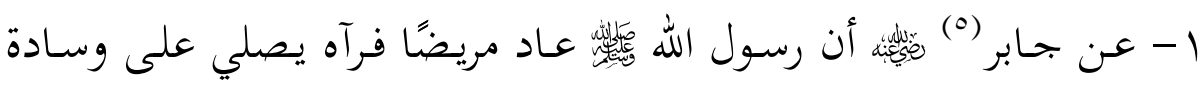

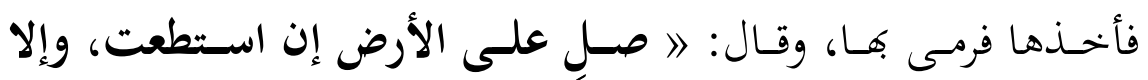

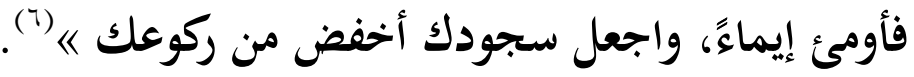

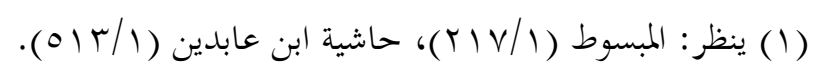

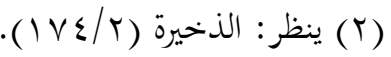

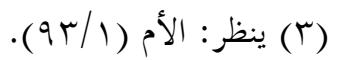

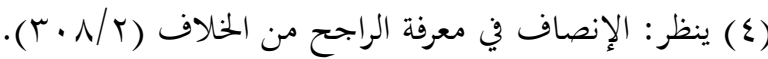

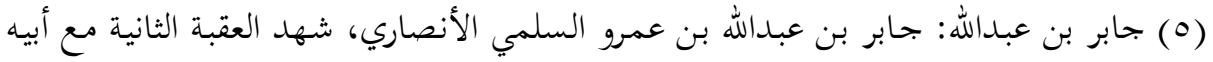

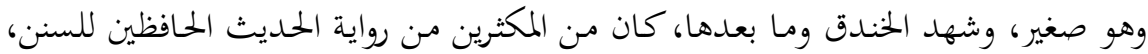

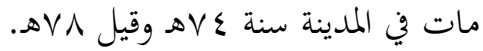

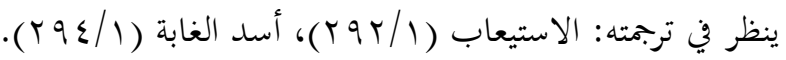

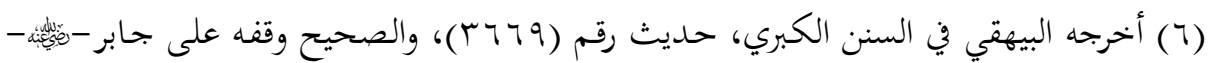

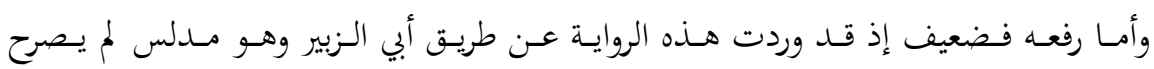
بالسماع.

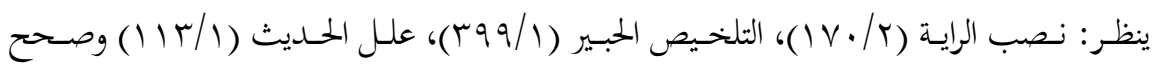

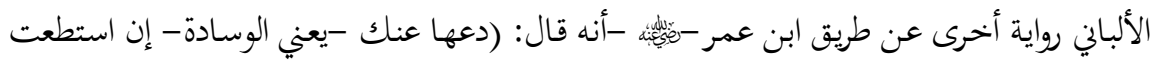

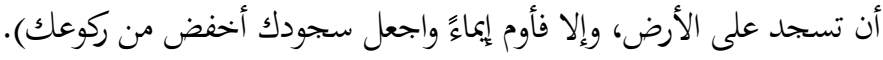
ينظر: السلسلة الصحيحة، حديث رقم (Tr الارب). 
Y - عن عطاء(1) قال: دخل ابن عمر على رجل فوجده يسجد على وسادة

\section{فنهاه، وقال: 》 أومئ واجعل السجود أخفض من الركوع 《(r).}

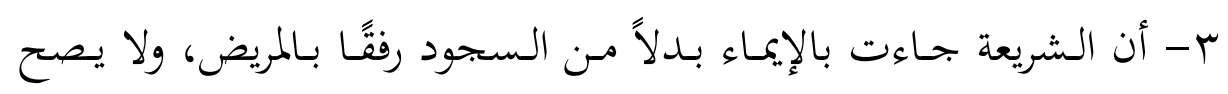

$$
\text { العدول عن البدل الشرعي بلا دليل (r). }
$$

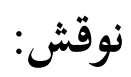

بأن المريض إذا لم يستطع القيام إلا بالاستناد على شيء فإنه يلزمه،

فكذا هنا عليه السجود على الموضع المرتفع أو الوسادة المرتفعة(ع).

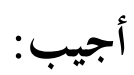

بـالفرق بين الحـالين، فالمريض إذا اعتمـد على شيء ليستتم قائمًا فإنه يأتي بهيئة القيـام، أمـا الساجد على الموضـع المرتفـع فلا يصدق عليـه الإتيـان بهيئة السجود(0)

(1) عطاء: عطاء بن أبي رباح بن أسلم وقيل -سالم- المكي، كان من أجلاء الفقهاء وتابعي مكة

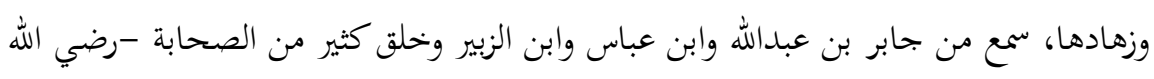

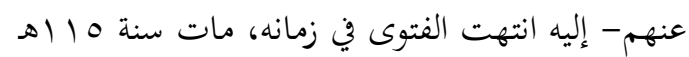

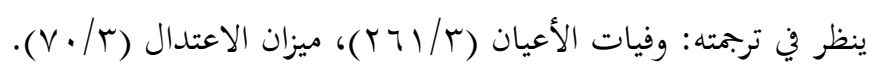

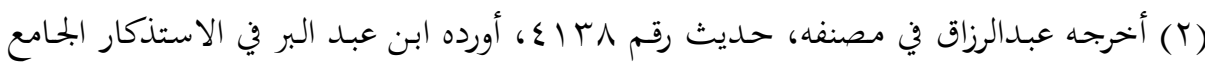

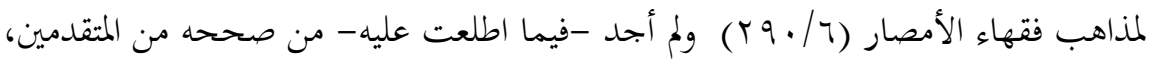

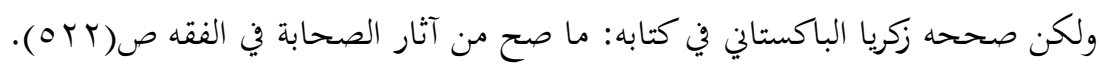

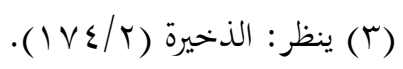

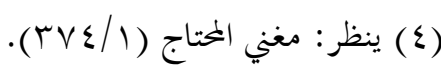

$$
\begin{aligned}
& \text { (0) ينظر: المرجع السابق. }
\end{aligned}
$$


القـول الثـاني: يكره سـود المـومئ على الموضـع المرتفـع أو الوسـادة

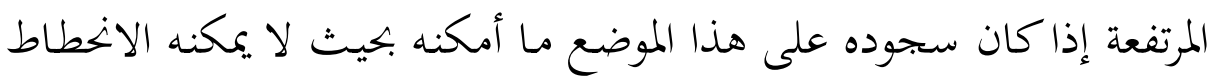

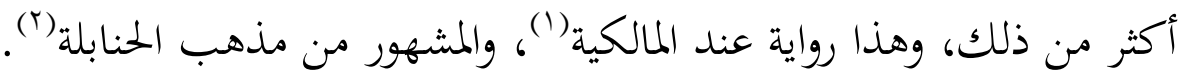

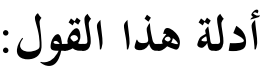

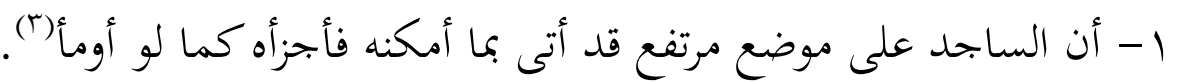
r- وجود الخلاف بين الفقهاء في هذه المسألة (๕).

بأن الاستدلال بمجرد وجود الخـلاف لا يستقيم دليلا ، قال شيخ الإسلام ابن تيمية-رممه الله-: ( إن تعليل الأحكام بالخلاف علة باطلة في نفس الأمر فإن الخلاف ليس من الصفات التي يعلق الشارع بها الأحكام في

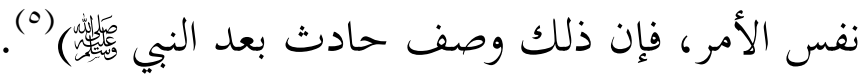
القـول الثالـث: جـواز سـود المومئ على الموضـع المرتفـع أو المكان المرتفع، وهذا مذهب أكثر الشافعية(') ورواية عند الحنابلة(1).

$$
\begin{aligned}
& \text { (1) ينظر : شرح التلقين (1 (1 ع §). }
\end{aligned}
$$

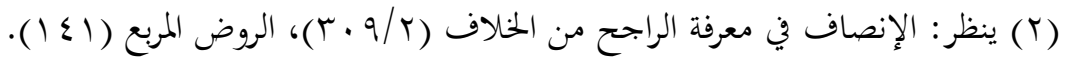

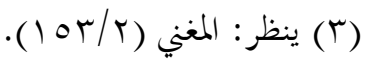

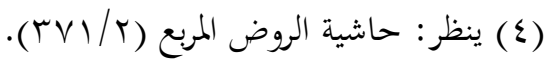

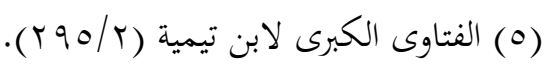

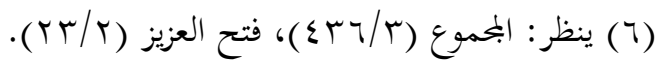




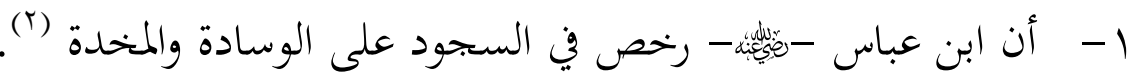

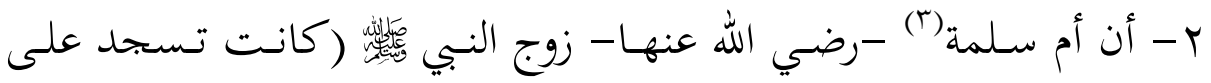

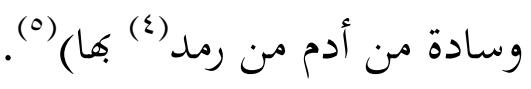

يمكن أن يناقش:

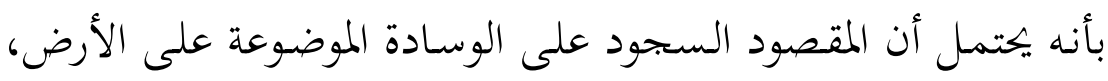
وهذا خارج محل الخلاف في هذه المسألة.

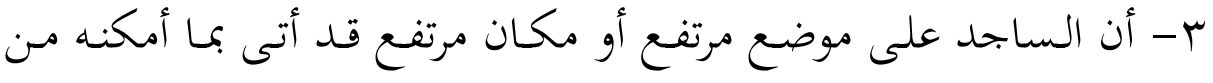
وضع رأسه فأجزأ كما لو أومأ) .)

$$
\begin{aligned}
& \text { (1) ينظر : الإنصاف في معرفة الراجح من الخلاف (r/N/ (r/). }
\end{aligned}
$$

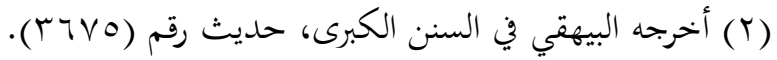

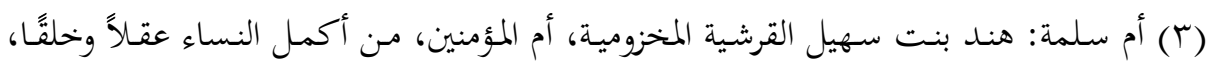

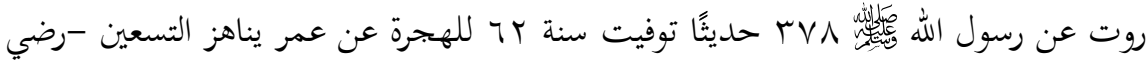

$$
\text { الله عنها وأرضاها-. }
$$

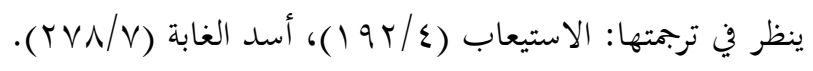

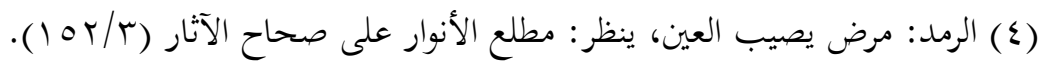

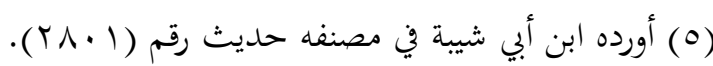

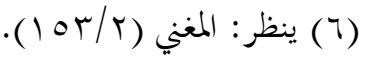




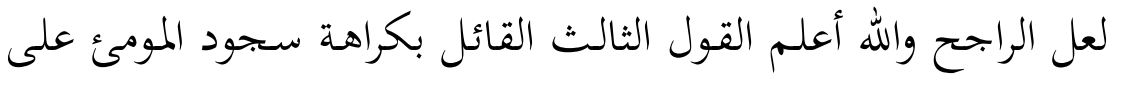

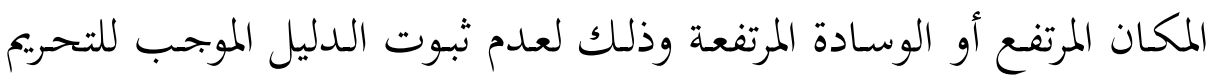
ولإمكان الإجابة على أدلة القائلين بالجواز.

\section{蝚}




\section{المبحث الثالث}

\section{حكم السجود على السجادة المرتفعة الحديثة}

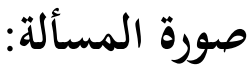

راعـت الشريعة أحسوال المرضى، وجعلـت صـالاقم على درجـات يبـدأ

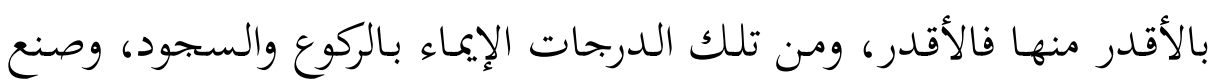

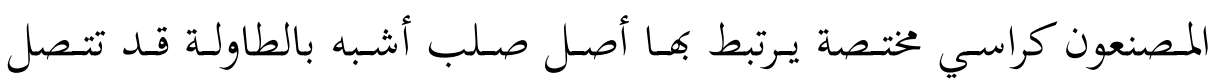
بالكرسي وقد تنفصل عنه، لكنها تمكن المصلي من السجود عليها وتكين جبهته منها ليشبه بذلك الساجد على الأرض.

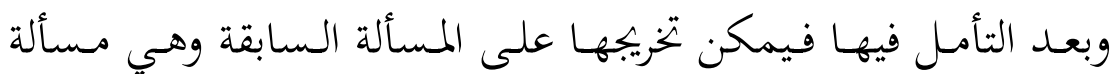
السجود على الموضـع المرتفـع أو الوسـادة المرتفعـة إذ الصورة واحـدة، وعليـهـ اختلف العلماء المعاصرون فيها على ثلاثة أقوال إليك بياها.

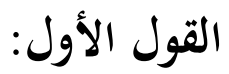

تحريم السجود على السجادة المرتفعة الحميثه وذهب إلى ذلك د. صالح

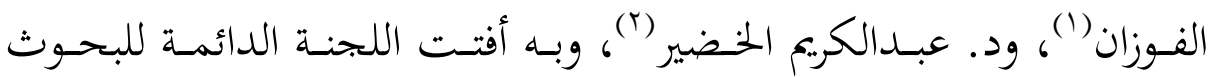

(1) ينظر : فتوى الشيخ بعنوان: ما حكم الصلاة على الكرسي ثم السجود على الطاولة. -vKHnVBEJKA=v?watch/com.youtube.www/l:https

$$
\text { (r) ينظر : شرح المحرر في الحديث (IV/r^) }
$$


استدل أصحاب هذا القول بأدلة القائلين بتحريم السجود على المكان

$$
\text { المرتفع أو الوسادة المرتفعة. }
$$

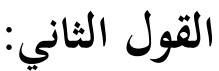

جواز السجود على السجادة المرتفعة الحديثة وذهب إليه من المعاصرين

$$
\text { د. دليل هذان القول: }
$$

أن السجود على هذه السجادة هو الأقرب إلى هيئة السجود من بجرد

$$
\text { الإيماء أو الانحناء اليسير (r). }
$$

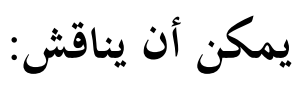

بأن فرض العاجز عن السجود هو الإيماء فيكتفى به.

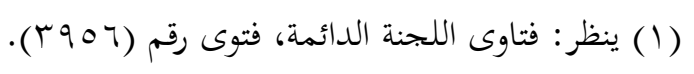

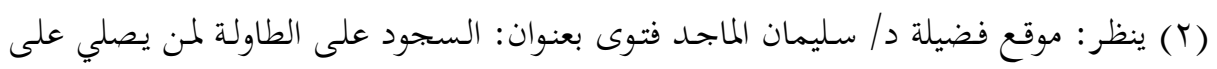

1) ґ^я=arno؟php.findnum/fatwa/com.salmajed.www//:https

$$
\text { (r) ينظر : : موقع فضيلة د/ سليمان الماجد فتوى بعنوان: السجود على الطاولة لمن يصلي على }
$$


كراهـة السجود على السجادة المرتفعة الحديثة وذهـب إلى ذلك بعض المعاصرين منهم: الشيخ ابن باز (') -رحمه اللهـ- والشيخ ابن عثيمسين (r) -رحمه

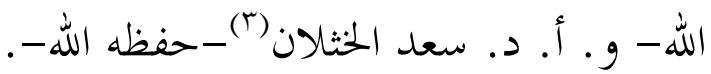

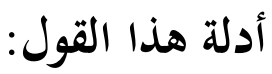

استدلوا بأدلة القائلين بكراهة السجود على الموضع المرتفع أو الوسادة

كما استدلوا بأن السجود عليها من قبيل التنطع وقد جاء في الحديث:

》 هلك المتنطعون، وقالها ثلاثًا «" (ع)

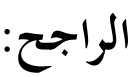

الراجح والله أعلم القول الثالث: القائل بكراهـة السجود على السجود

المرتفعـة الحلديثـة؛ إذ إغـا مماثلـة في الصصورة للمسسألة المخرجـة عليهـا السـابق ذكرها. والله أعلم.

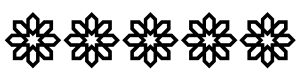

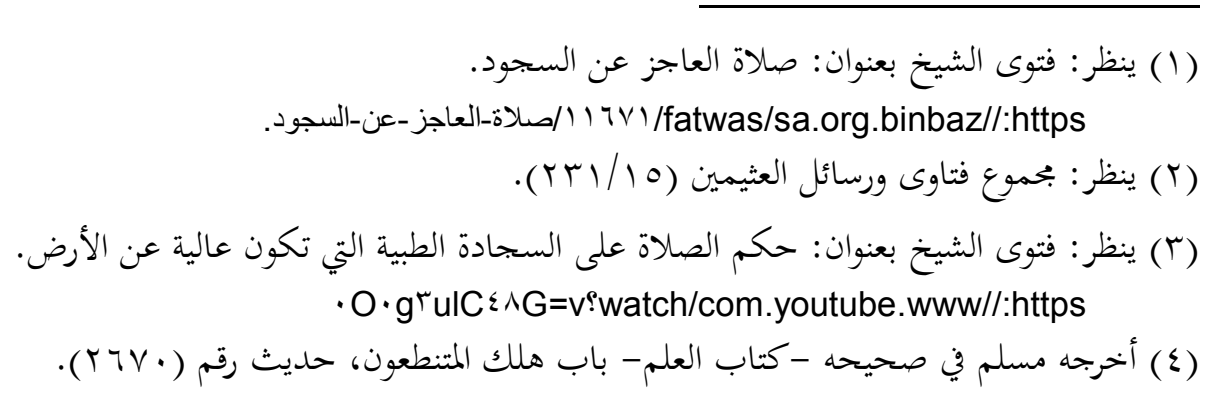




\section{الخاقتـة}

\section{الحمد لله حق حمده، والصلاة والسلام على رسوله وعبده وبعد:}

فإن مما تقتضيه قواعد البحث العلمي ما دأب عليه كثير من الباحثين

مـ ذكر خاتمة يدون فيها أهم نتائج البحثث بعد رحلة ميمونة بين بطون

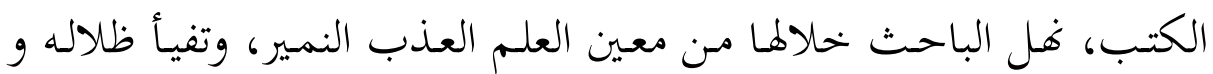

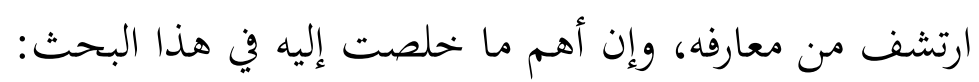

ا - أن المراد بالسجود على السجادة المرتفعة الحديثة هو: التعبد لله بالسجود

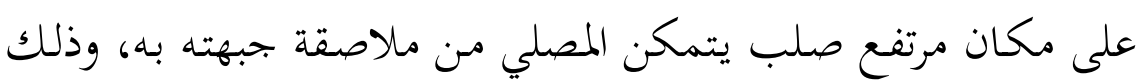

$$
\text { للمرضى ومن في حكمهم. }
$$

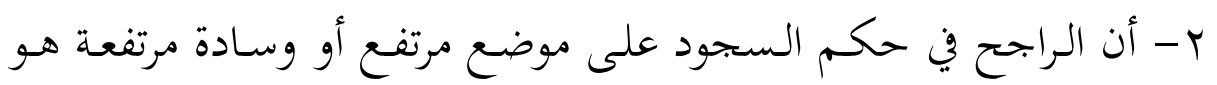

$$
\text { الكراهة مع الإجزاء. }
$$

r- أن صورة النازلة هي تصنيع كراسي يتصل بهـا موضع صلب أو ينفصل يتمكن المصلي الجحالس على الكرسي من وضع جبهته عليه كالساجد

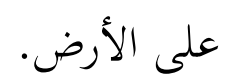

ع - أن حكم هـذه النازلة هو الكراهـة، فيكره للمصلي السجود على هـذه السجادة المرتفعة الحديثة مع الإجزاء. 
=

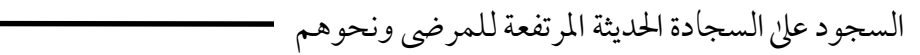

ه- أن الـشريعة راعـت المكلفـين في كـل أحسوالهم، إن حضرًا أو سـفرًا، وإن

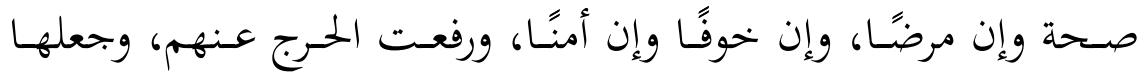
صالحة لكل زمان ملاءمة لكل مكان.

هذا والله أعلم وأحكم، ورحم الله امرءاً أعان ونصح وسدد، وصلى الله مسانه على نبينا محمد، وبارك وسلم تسليمًا كثيرًا.

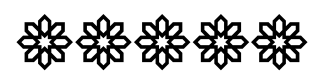




\section{فهرس المصادر والمراجع}

1- الاستيعاب في معرفة الأصحاب ليوسف القرطبي، تحقيق: علي محمد معوض، عادل أحمد عبد الموجود، دار الكتب العلمية، بيروت. r- أسد الغابة في معرفة الصحابة لعز الدين الجزري، تحقيق: خليل مأمون

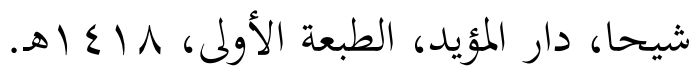

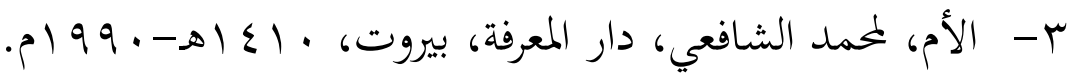

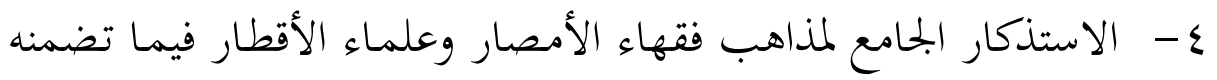

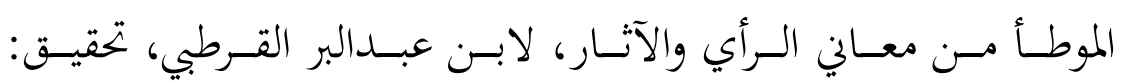

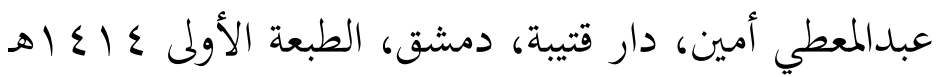

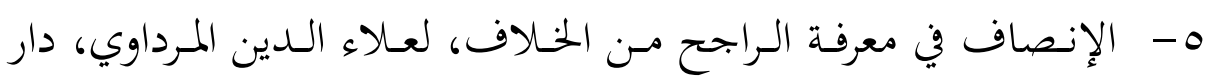

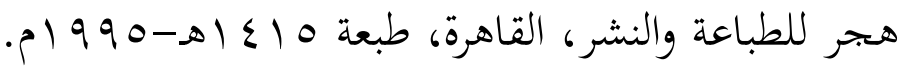
؟- بدائع الصنائع في ترتيب الشرائع للكاساني، دار الكتب العلمية، الطبعة

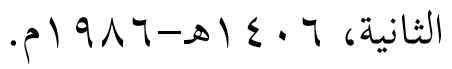

- V البناية شرح الهدايـة، لبدر الدين العيني، دار الكتب العلميـة، بيروت،

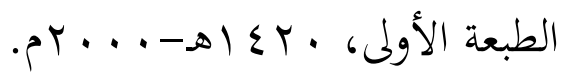

1- تاج العروس من جواهر القاموس،لممد بن محمد الحسيني الزبيدي، دار الهداية. - الم

9- ترتيب المدارك وتقريب المسالك لمعرفة أعلام مذهب مالك، لأبي الفضل 
عياض اليحصبي، دار الكتب العلمية، بيروت، الطبعة الأولى، م إع اهـ • إ-التعريفـات الفقهيـة، لمحمد البركتي، دار الكتـب العلميـة، الطبعة الأولى،

$$
\cdot r t \cdot r-\infty \mid \leq t r
$$

11 - التلخـيص الحبـير في تخـريج أحاديــث الرافعـي الكبـير، لابـن حجــر

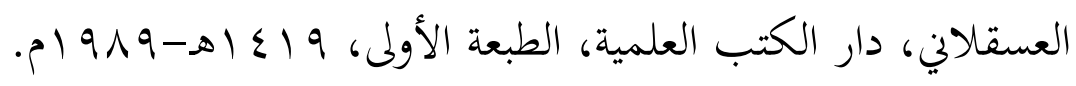

ب ا - تذذيب اللغة، محمد بن أحمد بن الأزهري الهروي، المحقق: محمد عوض

الناشر: دار إحياء التراث العربي - بيروت الطبعة: الأولى، ال ـ . بم.

ب ا - حاشية ابـن عابـدين (رد المحتـار على الدر المختـار) لابن عابـين، دار

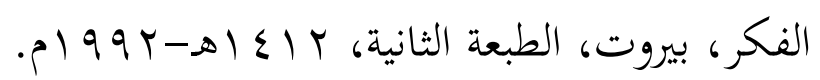

ع ا - حاشية الروض المربع شرح زاد المستقنع، لعبدالرحمن بن محمد بن قاسمه،

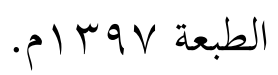

ه - الذخيرة للقرافي، تحقيق: محمد حجي وآخرون، دار الغرب الإسـامي، بيروت، الطبعة الأولى، ؛ 99 ام.

ا ا - الذخيرة، للقرافي، تحقيق: محمد حجي وآخرون، دار الغرب الإسلامي،

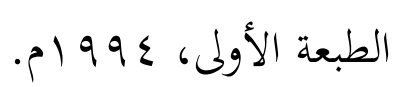

V - الروض المربع شـرح زاد المستقنع، لمنصور البهوتي، دار المؤيد، مؤسسة

$$
\text { الرسالة. }
$$

1 ا - السلسلة الصحيحة، لمحمد ناصر الدين الألباني. 9 1 - ميزان الاعتدال في نقـد الرجـال، لشمس الدين لأبي عبدالله الذهبي، تحقيق: علي محمد بيجاوي، دار المعرفة، بيروت، لبنان، ب ب اهـ. 
• · - السنن الكبرى، للبيهقي، تحقيق: عبدالله بـن عبدالمحسن التركي، مركز

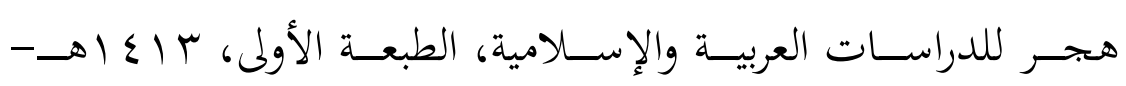

$$
\cdot p r \cdot 11
$$

اب - سـير أعـلام النبلاء، لـشمس الـدين أبي عبــالله محمــ الذهبي، تحقيـق: مجموعـة مسن المحققــن بإشـراف شـعيب الأرنـاؤوط، مؤسسسة الرسـالة، الطبعة الثالثة، 0 . ع 1 أهـ. r - - شرح السنة، لأبي الحسين البغوي، المكتب الإسـلامي- دمشق، الطبعة

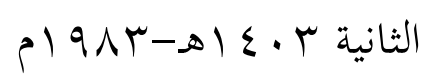

بr - شـرح التلقـين، لأبي عبــالله المـازري المـالكي، تحقيـق: محمـــ المختـار

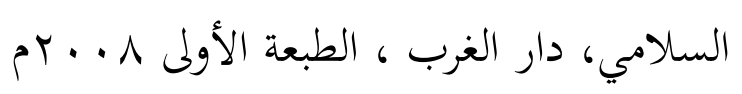
ع - - شرح المحرر في الحديث، لعبدالكريم الخضير، مذكرات مفرغة من دروس الحس

$$
\text { الشيخ المسجلة. }
$$

هب - الصحاح تـاج اللغـة وصححاح العربية، لأبي نصر إسماعيل الفـرابي ، دار

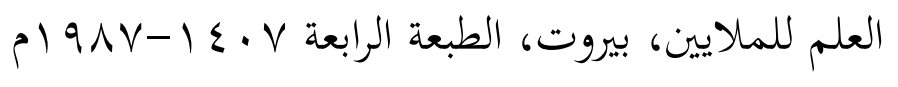

TY - صسحيح مسلم، لمحمـد بـن مسسلم القـشيري النيسابوري، مطبعـة بيـت الأفكار الدولية.

rV المخزومي، د إبراهيم السامرائي الناشر: دار ومكتبة الهلال. م ץ - الفتـاوى الكـبرى لابـن تيميـة، دار الكتـب العلميـة، الطبعـة الأولى، $. \$ 1 \leqslant \cdot 1$ 
و - -فتاوى اللجنة الدائمة، اللجنة الدائمة للبحوث العلمي والإفتاء، الإدارة العامة للطبع.

• ب-فـتح العزيـز شـرح الـوجيز، لأبي القاسـم الرافعي، تحقيـق: علـي محمـد عوض، عـادل أحمـد عبـدالموجود، دار الكتـب العلميـة، بـيروت، لبنـان،

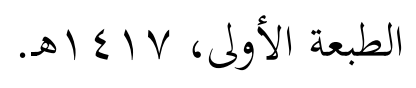

اب-فيض القدير شرح الجحامع الصغير، لزين الدين المناوي، المكتبة التجارية

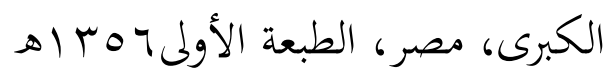

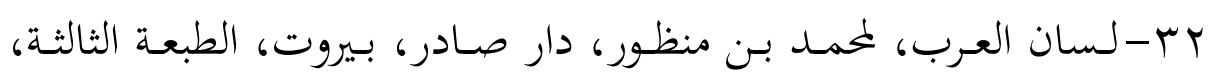
.

سr-ما صح من آثار الصحابة في الفقه، لزكريا بن غلام الباكستاني، دار ابن حزم للطباعة والنشر، بيروت، الطبعة الأولى. ع ب-مرعاة المفاتيح شرح مشكاة المصابيح، لأبي الحسين الرحماني المباركفوري،

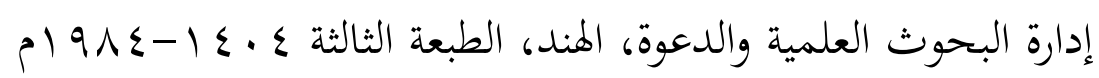
هب-المبسوط لمحمد السرخسي، دار المعرفة، بيروت، ع إع اهـ-بو9 أم. جب - البمموع شرح المهذب، يهيى بن شرف النووي، دار الفكر. VV فهد بن ناصر السليمان، دار الوطن، دار الثريا، طبعة ب إع اهـ. مץ-مـصنف ابـن أبي شـيبة، لأبي بكـر ابـن أبي شـيبة، دار الفـاروق للنشر والتوزيع. و ب- المصنف، لعبدالززاق الصنعاني، تحقيق: حبيب الرحمن الأعظمي، المحلس 


$$
\text { العلمي، الهند. }
$$

• ع -مطلع الأنوار على صحاح الآثار، لأبي إسحاق ابن قرقول، تحقيق: دار

الفلاح للبحث العلمي وتحقيق التراث، الطبعة الأولى، سبع اهـ.

إ -معجم لغة الفقهاء، لمحد قلعه جي وحامد قنيب، دار النفائس للطباعة

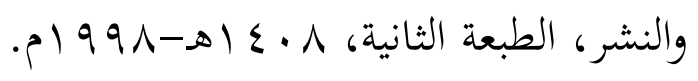

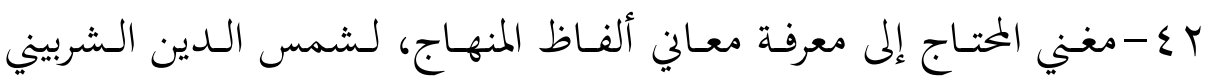
الشافعي، دار الكتب العلمية، الطبعة الأولى، 0 إع اهـ.

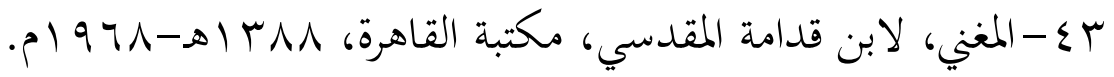
ع ع -مقــاييس اللغــة، لأبي الحــسين أحمـــ بــن فــارس بــن زكريـا، تحقيـق: عبدالسالام حممد هارون، دار الفكر، 99 ب اهـ. ــ -مـنح الجليـل شـرح مختصر خليـل، لأبي عبـدالله المـالكي، دار الفكـر،

$$
\cdot \rho|9 \wedge q-\infty| \leqslant \cdot q
$$

ج - -نصب الراية لأحاديـث الهداية، للزيلعي، تحقيق: محمد عوامـة، مؤسسة

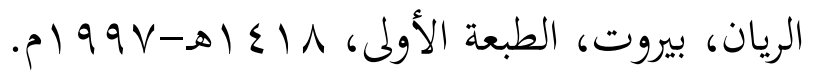

\& V وفيـات الأعيـان وأبنـاء الزمان، لأبي العبـاس شمس الـدين ابن خلكان، تحقيق: إحسان عباس، دار صارد، بيروت.

\section{称}




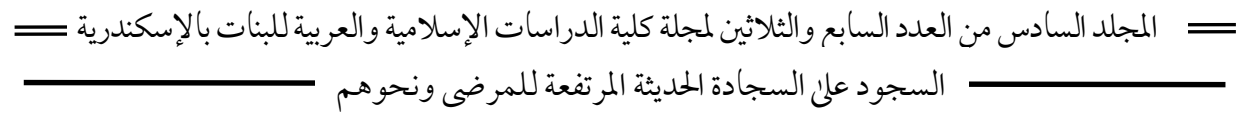

\section{References:}

1- alastieab fi maerifat al'ashab liusuf alqurtubi, tahqiqu: eali muhamad mueawada, eadil 'ahmad eabd almawjudi, dar alkutub aleilmiati, bayrut.

2- 'asad alghabat fi maerifat alsahabat lieizi aldiyn aljazari, tahqiqu: khalil mamun shiha, dar almuayidi, altabeat al'uwlaa, 1418hi.

3- al'um, limuhamad alshaafieii, dar almaerifati, bayrut, 1410h-1990m.

4- alaistidhkar aljamie limadhahib fuqaha' al'amsar waeulama' al'aqtar fima tadamanah almuataa min maeani alraay waluathar, liaibn eabdalbar alqurtubi, tahqiqu: eabdalmueti 'amin, dar qatibata, dimashqa, altabeat al'uwlaa $1414 \mathrm{~h}$

5- al'iinsaf fi maerifat alraajih min alkhilafi, lieala' aldiyn almardawi, dar hajr liltibaeat walnashri, alqahirati, tabeat 1415h-1995m.

6- badayie alsanayie fi tartib alsharayie lilkasani, dar alkutub aleilmiati, altabeat althaaniatu, 1406hi-1986m.

7- albinayat sharh alhidayati, libadr aldiyn aleaynii, dar alkutub aleilmiati, bayrut, altabeat al'uwlaa, 1420h-2000m.

8- taj alearus min jawahir alqamus, lmuhamad bin muhamad alhusaynii alzubaydii, dar alhidayati.

9- tartib almadarik wataqrib almasalik limaerifat 'aelam madhhab malki, li'abi alfadl eayad alyahsabi, dar alkutub aleilmiati, bayrut, altabeat al'uwlaa, $1418 \mathrm{~h}$

10- altaerifat alfiqhiatu, limuhamad albarakati, dar alkutub aleilmiati, altabeat al'uwlaa, 1422hi-2003m.

11- altalkhis alhabir fi takhrij 'ahadith alraafieii alkabiri, liabn hajar aleasqalani, dar alkutub aleilmiati, altabeat al'uwlaa, 1419hi-1989m.

12- tahdhib allughati, muhamad bin 'ahmad bin al'azharii alhurawii, almuhaqaqa: muhamad eawad alnaashir: dar 'iihya' alturath alearabii - bayrut altabeatu: al'uwlaa, 2001m.

13- hashiat abn eabidin (rd almuhtar ealaa aldiri almukhtari) liabn eabdin, dar alfikri, bayrut, altabeat althaaniati, 1412h-1992m. 


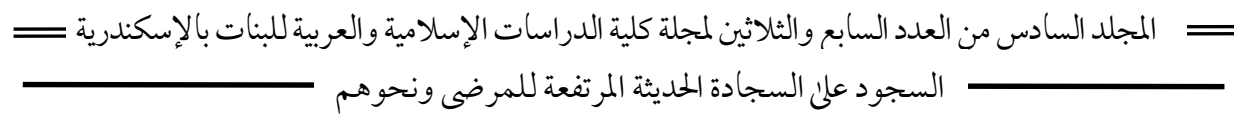

14- hashiat alrawd almurabae sharh zad almustaqnaea, lieabdalrahman bin muhamad bin qasimi, altabeat $1397 \mathrm{~m}$.

15- aldhakhirat lilqarafi, tahqiqu: muhamad hajiy wakhrun, dar algharb al'iislamii, bayrut, altabeat al'uwlaa, 1994m.

16- aldhakhirati, lilqarafi, tahqiqu: muhamad hajiy wakhrun, dar algharb al'iislamii, altabeat al'uwlaa, 1994m.

17- alrawd almurabae sharh zad almustaqnaea, limansur albuhuti, dar almuayidi, muasasat alrisalati.

18- alsilsilat alsahihati, limuhamad nasir aldiyn al'albani.

19- mizan alaietidal fi naqd alrajal, lishams aldiyn li'abi eabdallah aldhahbi, tahqiqu: eali muhamad bijawi, dar almaerifati, bayrut, lubnan, 1382h.

20- alsunan alkubraa, lilbihaqi, tahqiqu: eabdallah bin eabdalmuhsin alturki, markaz hajr lildirasat alearabiat wal'iislamiati, altabeat al'uwlaa, 1413h-2011m.

21- sir 'aelam alnubala'i, lishams aldiyn 'abi eabdallah muhamad aldhahbi, tahqiqu: majmueat min almuhaqiqin bi'iishraf shueayb al'arnawuwta, muasasat alrisalati, altabeat althaalithati, 1405hi.

22- sharh alsanati, li'abi alhusayn albughuii, almaktab al'iislamiadimashqa, altabeat althaaniat 1403hi-1983m

23- sharh altalqini, li'abi eabdallah almazri almalki, tahqiqu: muhamad almukhtar alsalami, dar algharb, altabeat al'uwlaa 2008m

24- sharah almuharir fi alhadithi, lieabdalkarim alkhudayr, mudhakirat mufraghatan min durus alshaykh almusajalati.

25- alsihah taj allughat wasihah alearabiati, li'abi nasr 'iismaeil alfarabii , dar aleilm lilmalayini, bayruta, altabeat alraabieat 1407-1987m

26- sahih muslimin, limuhamad bin muslim alqushayrii alniysaburi, matbaeat bayt al'afkar alduwliati.

27-aleayn, li'abi eabd alrahman alkhalil bin 'ahmad alfarahidii almuhaqaqa: d mahdii almakhzumi, d 'iibrahim alsaamaraayiyi alnaashir: dar wamaktabat alhilal. 


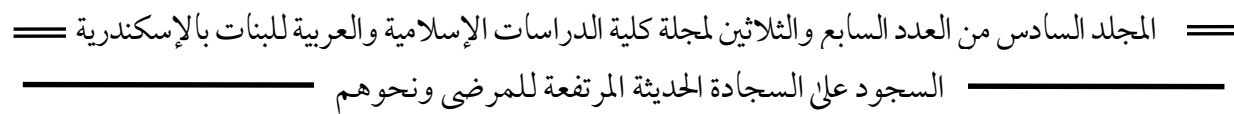

28- alfatawaa alkubraa liabn taymiati, dar alkutub aleilmiati, altabeat al'uwlaa, 1408hi.

29- fatawaa allajnat aldaayimati, allajnat aldaayimat lilbuhuth aleilmii wal'iifta'i, al'iidarat aleamat liltabei.

30- fath aleaziz sharh alwujiz, li'abi alqasim alraafiei, tahqiqa: eali muhamad eawad, eadil 'ahmad eabdalmawjudi, dar alkutub aleilmiati, bayrut, lubnan, altabeat al'uwlaa, 1417hi.

31- fid alqadir sharh aljamie alsaghiri, lizayn aldiyn almanawi, almaktabat altijariat alkubraa, masira, altabeat al'uwlaa1356h

32- lisan alearbi, limuhamad bin manzurin, dar sadir, bayruta, altabeat althaalithati, 1414hi.

33- ma saha min athar alsahabat fi alfiqah, lizakariaa bin ghulam albakistani, dar aibn hazam liltibaeat walnashri, bayrut, altabeat al'uwlaa.

34- mureat almafatih sharh mishkat almasabihi, li'abi alhusayn alrahmanii almubarikifuri, 'iidarat albuhuth aleilmiat waldaewati, alhinda, altabeat althaalithat 1404-1984m

35- almabsut limuhamad alsarakhsi, dar almaerifati, birut, 1414h$1993 \mathrm{~m}$.

36- almajmue sharh almuhadhabi, yahyaa bn sharaf alnawawii, dar alfikri.

37-majmue fatawaa warasayil aleuthaymin, limuhamad bin salih aleuthaymin, jame watartib fahd bin nasir alsulayman, dar alwatan, dar althirya, tabeat $1413 \mathrm{~h}$.

38- musanaf abn 'abi shaybata, li'abi bakr abn 'abi shibata, dar alfaruq lilnashr waltawziei.

39- almusanafu, lieabdalrazaaq alsaneani, tahqiqu: habib alrahman al'aezami, almajlis alealmiu, alhindu.

40- matlae al'anwar ealaa sihah aluathar, li'abi 'iishaq abn qarqula, tahqiqu: dar alfalah lilbahth aleilmii watahqiq altarathu, altabeat al'uwlaa, 1433 hi. 


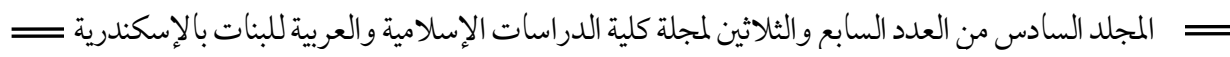

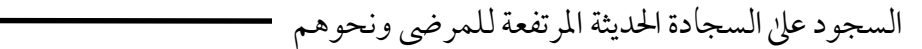

41- maejam lughat alfuqaha'i, limuhamad qaleah ji wahamid qanibi, dar alnafayis liltibaeat walnashri, altabeat althaaniati, 1408h-1998m.

42- mighni almuhtaj 'iilaa maerifat maeani 'alfaz alminhaji, lishams aldiyn alshirbinii alshaafieii, dar alkutub aleilmiati, altabeat al'uwlaa, 1415hi.

43- almighni, liabn qudamat almaqdisi, maktabat alqahirati, 1388hi1968mi.

44- maqayis allughati, li'abi alhusayn 'ahmad bin faris bin zakaria, tahqiqu: eabdalsalam muhamad harun, dar alfikri, 1399hi.

45- mnah aljalil sharh mukhtasar khalil, li'abi eabdallah almaliki, dar alfikri, 1409h-1989m.

46- nasb alraayat li'ahadith alhidayati, lilziylei, tahqiqu: muhamad eawaamt, muasasat alrayan, bayrut, altabeat al'uwlaa, 1418h-1997m.

47- wfiaat al'aeyan wa'abna' alzaman, li'abi aleabaas shams aldiyn aibn khalkan, tahqiqu: 'iihsan eabaas, dar sard, birut.

\section{0\%}

